\title{
An impacted urethral stone: a rare cause of acute urinary retention in women-case report
}

\author{
Babatunde K. Hamza ${ }^{1 *} \mathbb{0}$, Ahmad Bello², Musliu Adetola Tolani² ${ }^{2}$ Jerry G. Makama and Nuhu Yusuf ${ }^{1}$
}

\begin{abstract}
Background: Urethral calculi are rare, representing 1-2\% of all calculi affecting the urinary tract. Impacted urethra calculi are commoner in males due to anatomical differences between the male and female urethra. The treatment approach is determined by the size and location of the stone, associated anomalies and available facilities.
\end{abstract}

Case presentation: We present the case of 35-year-old woman who presented with acute urinary retention secondary to an impacted urethral stone. The calculus could not be removed through the external urethral meatus due to the size of the stone. She had cystolithotomy after retrograde manipulation to the bladder. She did well postoperatively. This line of management was based on the size of the stone, and the available facilities which are typical of many hospitals in developing countries.

Conclusions: Urethral calculi are extremely rare in women. The treatment should be individualized.

Keywords: Stone, Urethra, Female

\section{Background}

Urolithiasis is the third-most common disease of the urinary tract, exceeded only by urinary tract infections and pathologic conditions of the prostate [1]. Urinary tract calculi commonly affect the kidney, ureter and bladder. Urethral calculi are rare, representing $1-2 \%$ of all calculi affecting the urinary tract [2]. Urethral calculi are extremely rare in females [3]. This is probably as a result of a shorter urethra, which has a straight course. The male urethra is much longer and makes almost a 90-degree curvature at the bulbar urethra. This angulation may contribute to the increased predisposition of males to urethral calculi. In addition, there is luminal size disparity in the male urethra, the penile being of smaller diameter as compared to the bulbar urethra.

Urethral calculi can be classified as primary and secondary or migratory urethral calculi [4]. Majority of

\footnotetext{
*Correspondence: ridwankolapo@yahoo.com

${ }^{1}$ Kaduna State University/Barau Dikko Teaching Hospital, Kaduna, Nigeria Full list of author information is available at the end of the article
}

urethral calculi are secondary, their primary site is usually the bladder or upper urinary tract [5]. Primary or de novo urethral calculi result from condensation of stone materials on foreign body or around the areas of stasis such as urethral diverticulum.

A literature review of impacted urethral calculi in women revealed isolated case reports. In one of the largest series on impacted urethral stone, a retrospective 10 year period at the Usman Danfodio University Teaching Hospital, Sokoto, in North- western Nigeria, only one female (2.5\%) was seen out of a total of forty patients [6].

We present a 35-year-old woman with acute urinary retention secondary to an impacted urethral stone. Our treatment approach is relevant to many centers in developing countries. Amole et al. reported on successful extraction of an impacted female urethral stone via the external meatus after copious lubrication [7]. This line of treatment was not successful in this patient due to the size of the stone.

We aim to describe successful management of an impacted urethral stone in a woman, who presented to 
a low resource center that lacks the modern facilities for the treatment of urolithiasis.

\section{Case presentation}

A 35-year-old woman presented to the emergency department with sudden inability to pass urine. No prior history of irritative and obstructive lower urinary tract symptoms. There was no prior history of hematuria, lithoturia or abdominal pain. No antecedent history of fullness or protrusion per vaginam either.

Examination revealed an acutely ill looking woman in distress from pain. The bladder was distended and palpable. On vaginal examination, a mass palpable in the region of the urethra, protruding through the external meatus. The mass was hard when felt through the meatus (see Fig. 1).

A diagnosis of acute urinary retention secondary to impacted urethral stone was made.

A gentle attempt to remove the stone through the meatus failed due to the size of the stone.

Patient was planned for an emergency cystolithotomy after a retrograde manipulation of the stone into the bladder.

Through a pfannensteil incision the bladder was accessed, and cystotomy was done. The stone was

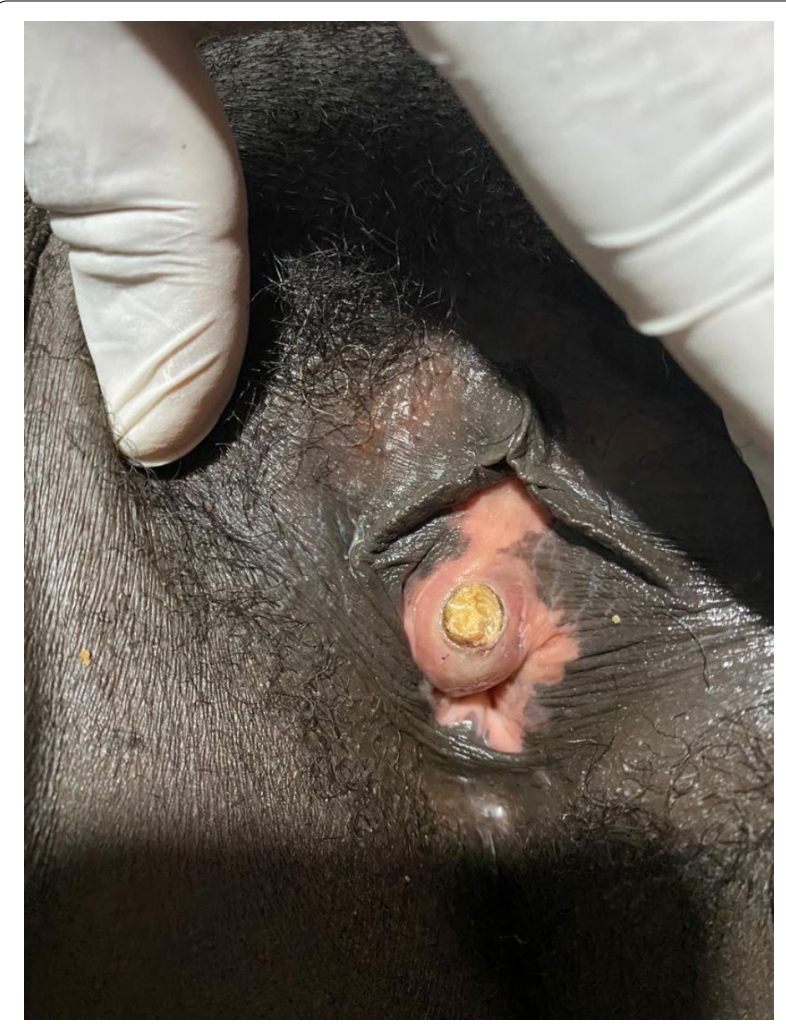

Fig. 1 Stone image at vaginal examination extracted from the bladder (see Fig. 2). It measured about 2 by 1 by $0.5 \mathrm{~cm}$ (see Fig. 3). The bladder was further explored and no abnormality was detected. The bladder was repaired in two layers after passing a size 18F urethral catheter.

Abdominal ultrasound and plain abdominal X-ray (KUB) were done postoperatively, and they were found to be normal.

Patient was maintained on indwelling urethral catheter for 7 days. Following the removal of the catheter, she was able to void without any difficulty. There was no urinary incontinence.

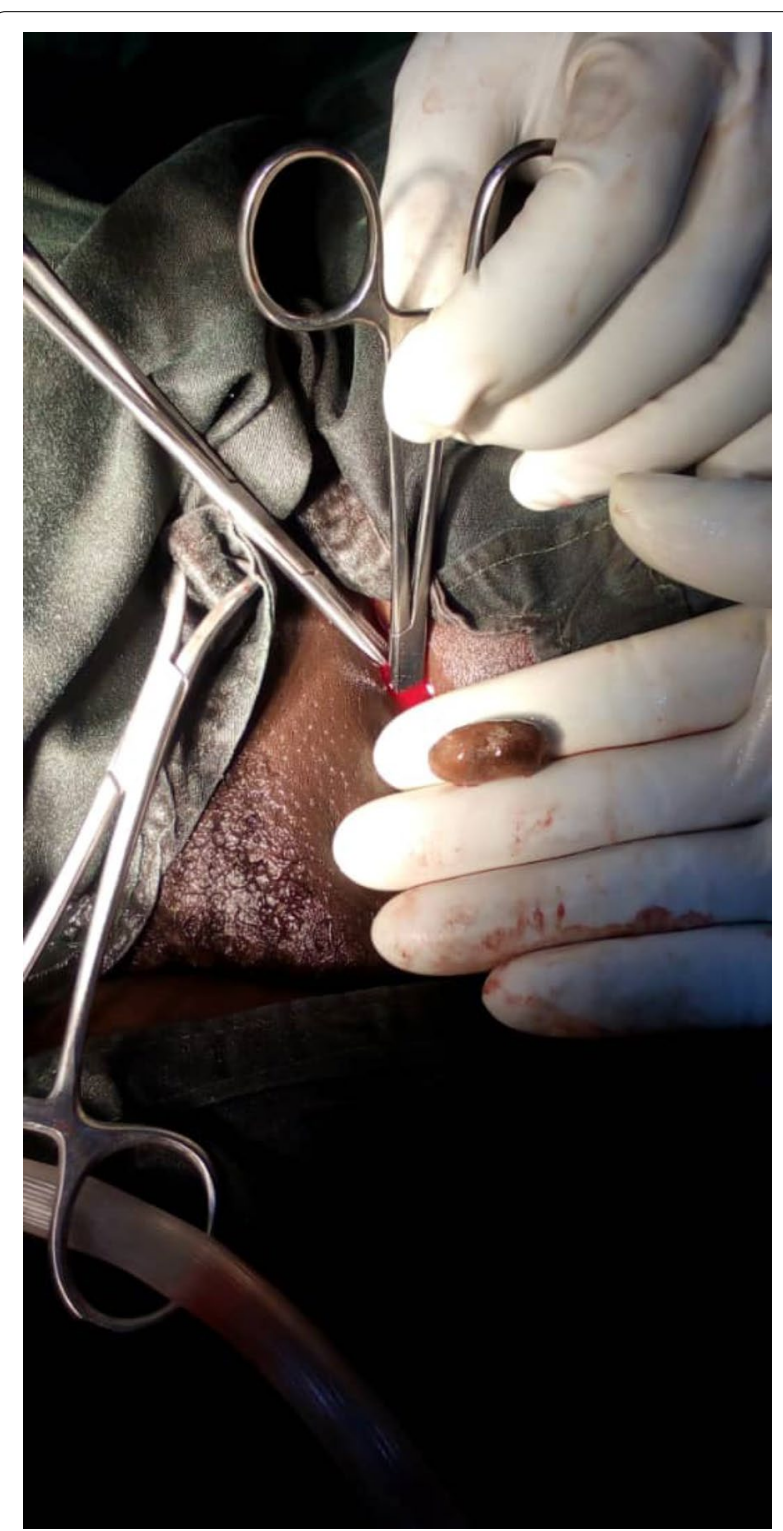

Fig. 2 Stone image during cystolithotomy 


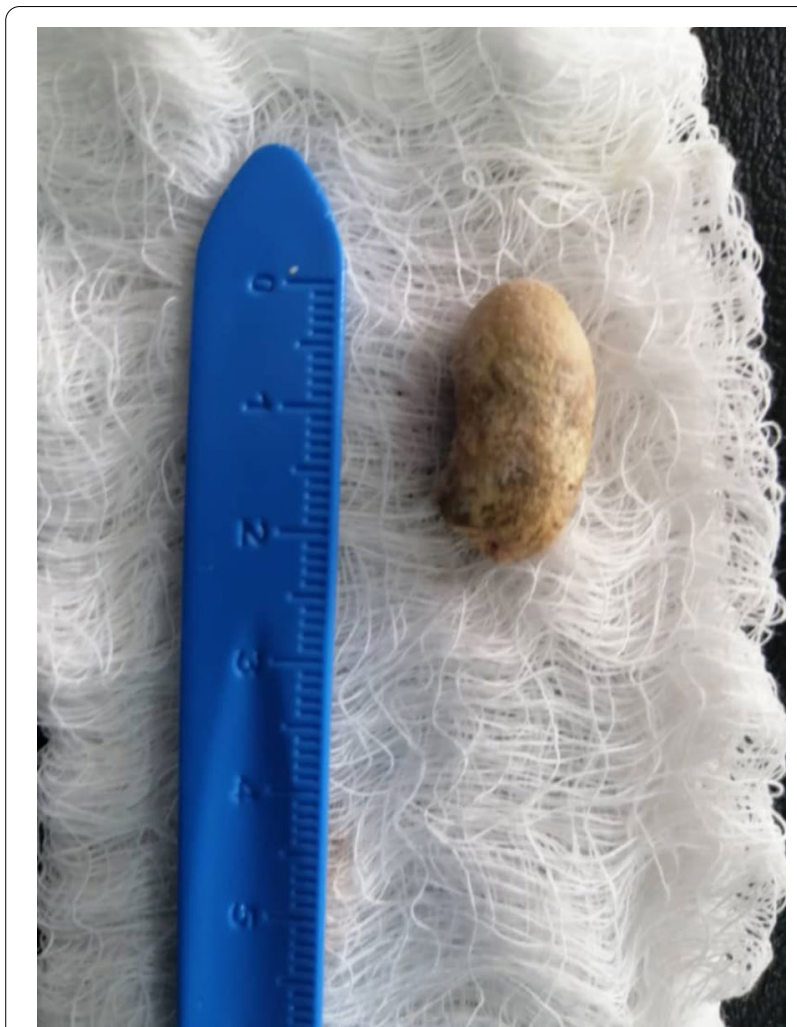

Fig. 3 Stone after removal

\section{Discussion}

Acute urinary retention is a painful inability to pass urine that is relieved by bladder drainage [8]. It is commoner in males due diseases of the prostate and urethra. Incidence of urinary retention in women is estimated at 0.07 per 1,000 inhabitants each year and relatively uncommon compared to men [9]. The male to female incidence is about 13:1 [10]. Özveren et al. in a retrospective review of 138 female who presented with acute urinary retention found that none of these patients had impacted urethral calculi as a cause of the retention [11].

The factors that determine the treatment approach of urethral stones include the size of the stone, location of the stone, associated structural anomalies and the available facilities. Small stones can easily be milked out through the urethral meatus after lubrication with xylocaine jelly, but this carries the potential risk of mucosal injury and the subsequent development of urethral stricture [12]. In this patient, the stone could not be milked out due its large size. Stones that cannot be removed through the urethral meatus can be pushed into the bladder, and then disintegrated with intracorporeal lithotripters (pneumatic, laser, ultrasonic and electrohydraulic). The use of extracorporeal shockwave lithotripsy after pushback into the bladder has been reported, it has a success rate of about $60 \%$ [13]. In situ lithotripsy of an impacted stone is a feasible option, but there is risk of urethral injury with the use of electrohydraulic and pneumatic lithotripters; however, this risk is minimal with laser lithotripsy[14]15. Urethrolithotomy has been described for impacted male urethral stone if the stone is in the anterior urethra [6]. However in females, the urethral sphincter surrounds the urethra at the middle third of its length [16], urethrolithotomy or meatotomy can result into urinary incontinence from possible to injury to the external urethral sphincter.

The diagnosis was entirely clinical in this patient. She presented with sudden onset urinary retention with no antecedent history lower urinary symptoms or hematuria, and the stone was visible on the external urethral meatus during the vaginal examination. We opted for a cystolithotomy after retrograde manipulation into the bladder. This is an option for treatment in a low resource setting where facilities for lithotripsy are not readily available.

\section{Conclusions}

Urethra calculi are a possible cause of acute urinary retention in women. Meticulous history and thorough examination can reveal the diagnosis. The treatment should be individualized, taking into consideration, the size and location of the stone, associated anomalies and available facilities.

\section{Acknowledgements}

Not applicable.

\section{Authors' contributions}

BKH Project development, manuscript writing, editing and case management. AB Project development, editing. MAT manuscript writing and editing. JGM manuscript writing and editing. NY manuscript writing and editing. All authors have read and approved the manuscript.

\section{Funding}

None.

Available data and materials

They are available on request.

\section{Declarations}

\section{Ethics approval and consent to participate}

This study was approved by the Health research ethics committee (HREC) of Barau Dikko Teaching Hospital Kaduna (Reference number: BDTH/MAC/ GEN/134/NOL/1). A written informed consent was obtained from the patient.

\section{Consent for publication}

A written consent was given by the patient.

\section{Competing interests}

The authors declare that they have no competing interests.

\section{Author details}

${ }^{1}$ Kaduna State University/Barau Dikko Teaching Hospital, Kaduna, Nigeria. ${ }^{2}$ Ahmadu Bello University Zaria/Ahmadu Bello University Teaching Hospital, Zaria, Nigeria. 
Received: 29 April 2021 Accepted: 9 August 2021

Published online: 27 September 2021

\section{References}

1. Stoller ML. Urinary stone disease. In: Smith's general urology, 17 th ed. McGraw-Hill; 2008. p. 249.

2. Koga S, Arakaki Y, Matsuoka M, Ohyama C (1990) Urethra calculi. Br J Urol 65(3):288-289

3. Arya MC, Kumar L, Kumar R, Baid M, Tiwari R (2016) Large urethral calculi in females. Int J Sci Appl Res 3(4):1-4

4. Arvind PD, Mahesh RD. Lower urinary calculi. In Campbell-Walsh-Wein urology, 12th edn. Elseiver; 2021, p. 2117.

5. Debenham RK (1930) Urethral calculi. BJU Int 2(2):112-121

6. Peter Agwu N, Abdulwahab-Ahmed A, MuhammaduSadiq A, UgbedeOyibo E, Arzika MI (2020) Management of impacted urethral calculi: an uncommon cause of acute urine retention in North-western Nigeria. Int J Clin Urol 4(1):1

7. Amole IO, Adesina SA, Adegoke AO, Durodola AO et al (2016) Impacted urethral stone in a female: case report. Int J Med Pharm Case Rep 2:1-4

8. Muhammed A, Abubakar A (2012) Pathophysiology and management of urinary retention in men. Arch Int Surg 2(2):63-69

9. Lee CY, Kim CS, Cho WJ (2015) Characteristics of urinary retention in female inpatients managed with medical treatments. Korean J Urol 56(12):817-822
10 Meycha A, Marcus JD (2010) Etiology and management of urinary retention in women. Indian J Urol 26(2):230-235

11. Özveren B, Keskin S (2016) Presentation and prognosis of female acute urinary retention: analysis of an unusual clinical condition in outpatients. Urol Ann 8(4):444-448

12. Sungur M, Baykam M, Calışkan S, Lokman U (2018) Urethral calculi: a rare cause of acute urinary retention in women. Turk J Emerg Med 18(4):170-171

13. El-Sharif AE, Prasad K (1995) Treatment of Urethral stones by retrograde manipulation and extracorporeal shockwave lithotripsy. Br J Urol 76:761-764

14. Kamal BA, Anikwe RM, Darawani H et al (2004) Urethral calculi, presentation and management. BJU Int 93:549-552

15. Koh CJ, De Fillipo RE, Bochner BH et al (1999) Extensive bladder and urethral calculi detected with computed tomography: diagnosis and management. J Urol 162:158

16. Yucel S, Baskin LS (2004) An anatomical description of the male and female urethral sphincter complex. J Urol 171:1890-1897

\section{Publisher's Note}

Springer Nature remains neutral with regard to jurisdictional claims in published maps and institutional affiliations.

\section{Submit your manuscript to a SpringerOpen ${ }^{\circ}$ journal and benefit from:}

- Convenient online submission

- Rigorous peer review

- Open access: articles freely available online

- High visibility within the field

- Retaining the copyright to your article

Submit your next manuscript at $\gg$ springeropen.com 